\title{
OPERATION AND DEFENSIVE ROLE OF “GIN TRAPS" IN A COCCINELLID PUPA (CYCLONEDA SANGUINEA) ${ }^{1}$
}

\author{
By Thomas EISNER AND MARIA EISNER \\ Section of Neurobiology \& Behavior \\ W347 Mudd Hall, Cornell University, \\ Ithaca, New York, 14853-2702
}

\section{INTRODUCTION}

The term gin traps, as applied to insects, was introduced by Hinton (1946) to denote certain intersegmental pinching devices commonly found in pupae of Coleoptera and Lepidoptera. Gin traps are essentially mouth-like elaborations of the intersegmental regions of the pupal abdomen. Typically they consist of localized, more or less pronounced intersegmental clefts, flanked by heavily sclerotized margins fashioned as jaws. Ordinarily, in the resting pupa, these jaws are held agape. But when the pupa is disturbed and thereby prompted to flex or rotate its abdomen, the jaws open and close in what is in effect a biting action (Hinton 1946). Gin traps occur singly or multiply in pupae, and may be medial or lateral in position. Hinton $(1946,1951,1955)$ noted their presence in 10 families of Coleoptera and 3 families of Lepidoptera. The jaws of gin traps are variously serrate, and on occasion even elaborately dentate (Hinton 1946).

Data on the defensive effectiveness of gin traps are scant. Hinton (1946) presents evidence that the devices can deter predaceous mites, but he did not test whether they protect also against such ubiquitous enemies as ants. We here describe the gin trap mechanism of a coccinellid pupa, and provide evidence of its defensive role vis à vis ants. Hinton (1955) reports the presence of dorsal gin traps in "many" coccinellid pupae, but does not describe the structures in these beetles.

Our observations were done on pupae of a single species of Coccinellidae, Cycloneda sanguinea, a beetle found throughout the

\footnotetext{
${ }^{1}$ Paper no. 110 of the series Defense Mechanisms of Arthropods. This paper is affectionately dedicated to our friend, Frank M. Carpenter, under whom one of us (T. E.) had the great pleasure of doing his doctoral work.

Manuscript received 13 March 1992
} 
southern United States and ranging southward into Argentina (Gordon 1985). We studied the beetle at two locations: the Archbold Biological Station, near Lake Placid, Highlands County, Florida, and at Cave Creek Canyon, in the environs of Portal, Cochise County, Arizona. Pupae were either collected on various plants in the wild or obtained in the laboratory from field-collected larvae fed on aphids.

\section{MoRPHOLOGY AND MeChANISM}

The pupal gin traps of $C$. sanguinea consist of four deep clefts, between abdominal tergites 3-4, 4-5, and 6-7 (Fig. 1). The anterior jaws of these traps are the posterior margins of tergites 3 to 6 . The corresponding posterior jaws are the anterior margins of tergites 4 to 7 . The free edge of each anterior jaw is minutely serrate (Fig. 3, lower right), unlike the edge of the opposing posterior jaw, which is relatively smooth (not shown). When the pupa is at rest, with its body bent forward and ventral surface nearly recumbent against the substrate, the four gin traps are essentially "set" for action, with their jaws widely open (Fig. 1). Stimulating such a pupa mechanically with a brush nearly always caused it to straighten out abruptly by flexing the abdomen upward, in a quick flipping motion that caused the four traps to clamp shut. Stimulating the pupa with a single bristle from such a brush tended usually not to elicit the reflexive flip, unless the bristle was specifically applied to either the cleft or jaws of a trap (Fig. 2, top). Repeated stimulation with brush or bristle often evoked numbers of flips, executed in rapid succession. The flipping reflex is quick and appears intended to cause no more than a momentary "snapping" of the traps. The jaws, when closed, fit snugly, with minimal overlap (the serrated edge of each anterior jaw fits just beneath the corresponding posterior jaw).

\section{AnT ATtacks}

Tests were done in which individual $C$. sanguinea pupae were exposed to attacks by worker fire ants (Solenopsis invicta). The tests were staged in small cylindrical chambers $(3.5 \mathrm{~cm}$ height; 8 $\mathrm{cm}$ floor diameter; floor covered with sand) and monitored with a stereomicroscope. The ants, taken some hours beforehand from a colony on the grounds of the Archbold Biological Station, were 

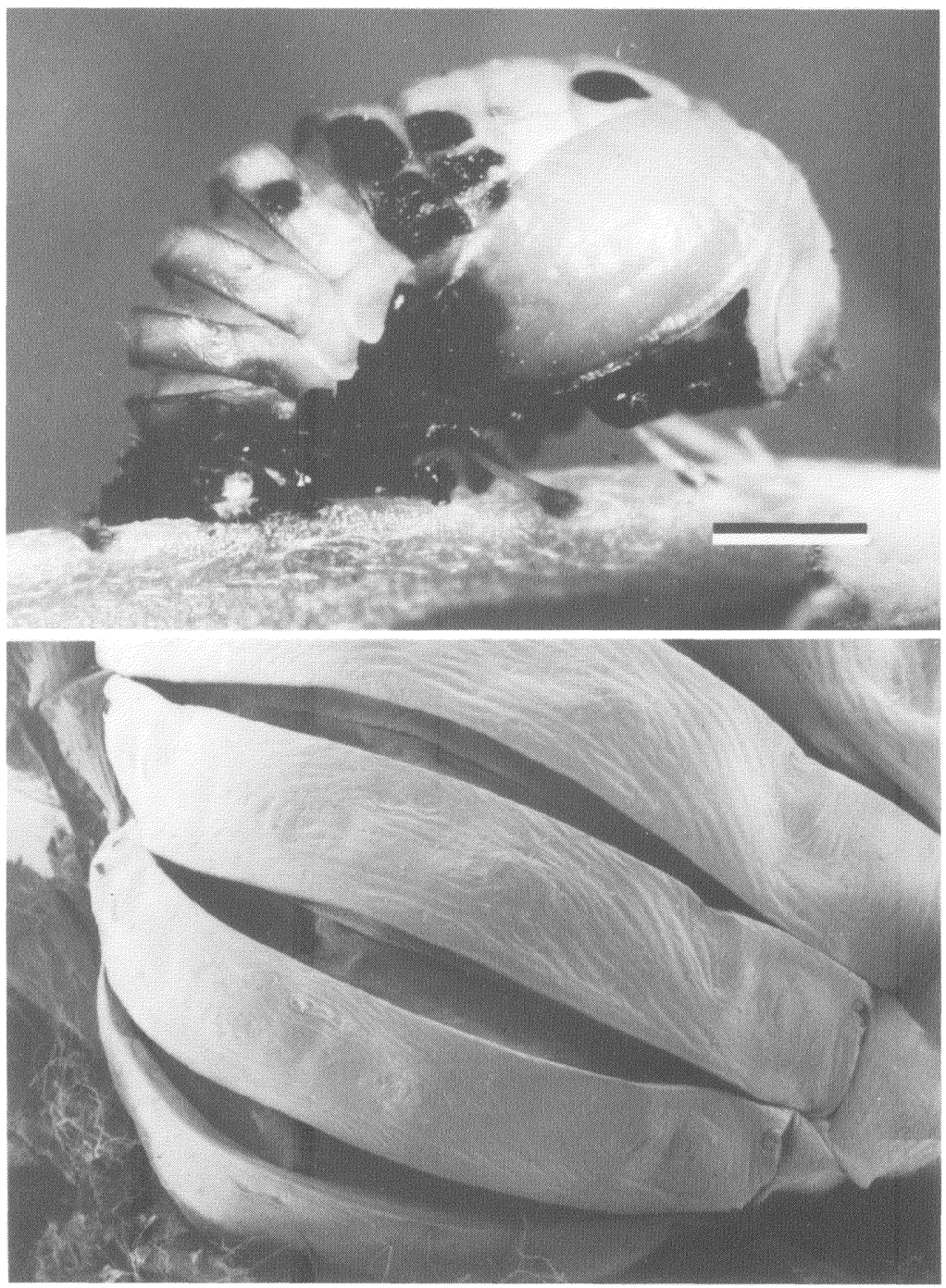

Figure 1. (Top) Pupa of Cycloneda sanguinea in resting position, lateral view. The four deep intersegmental clefts on the back of the abdomen denote the gin traps. (Bottom) Same, surface view of gin traps (anteriormost gin trap is only partly shown) (scanning electronmicrograph). Reference bar, top figure $=1 \mathrm{~mm}$. 

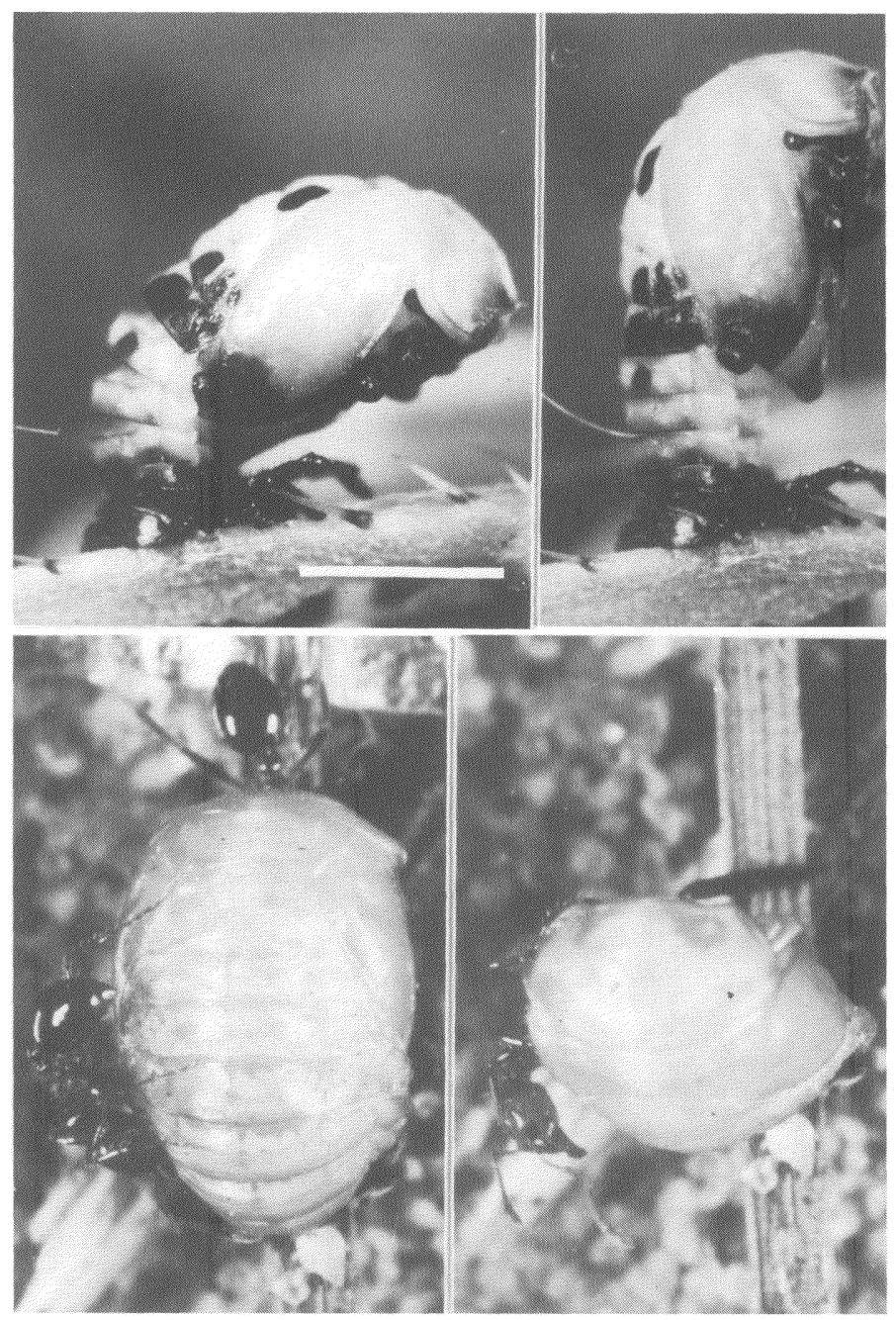

Figure 2. (Top) Stimulation of $C$. sanguinea pupa with bristle of a brush. On left, pupa is in resting position, and bristle is approaching posteriormost gin trap. On right, bristle has been inserted into the trap, and pupa has responded by executing the straightening reflex (the "flip"), causing the trap to clamp down on the bristle. (Bottom) Attack of fire ants (Solenopsis invicta) upon a C. sanguinea pupa. On left, an ant has mounted the pupa and is inspecting the region of the gin traps. On right, the pupa has responded by flipping, causing the ant to discontinue its probings. Note that mandibles of ant are still agape (in the tests, following such initial reaction, ants usually departed from pupae). Reference bar in upper left $=2 \mathrm{~mm}$. 

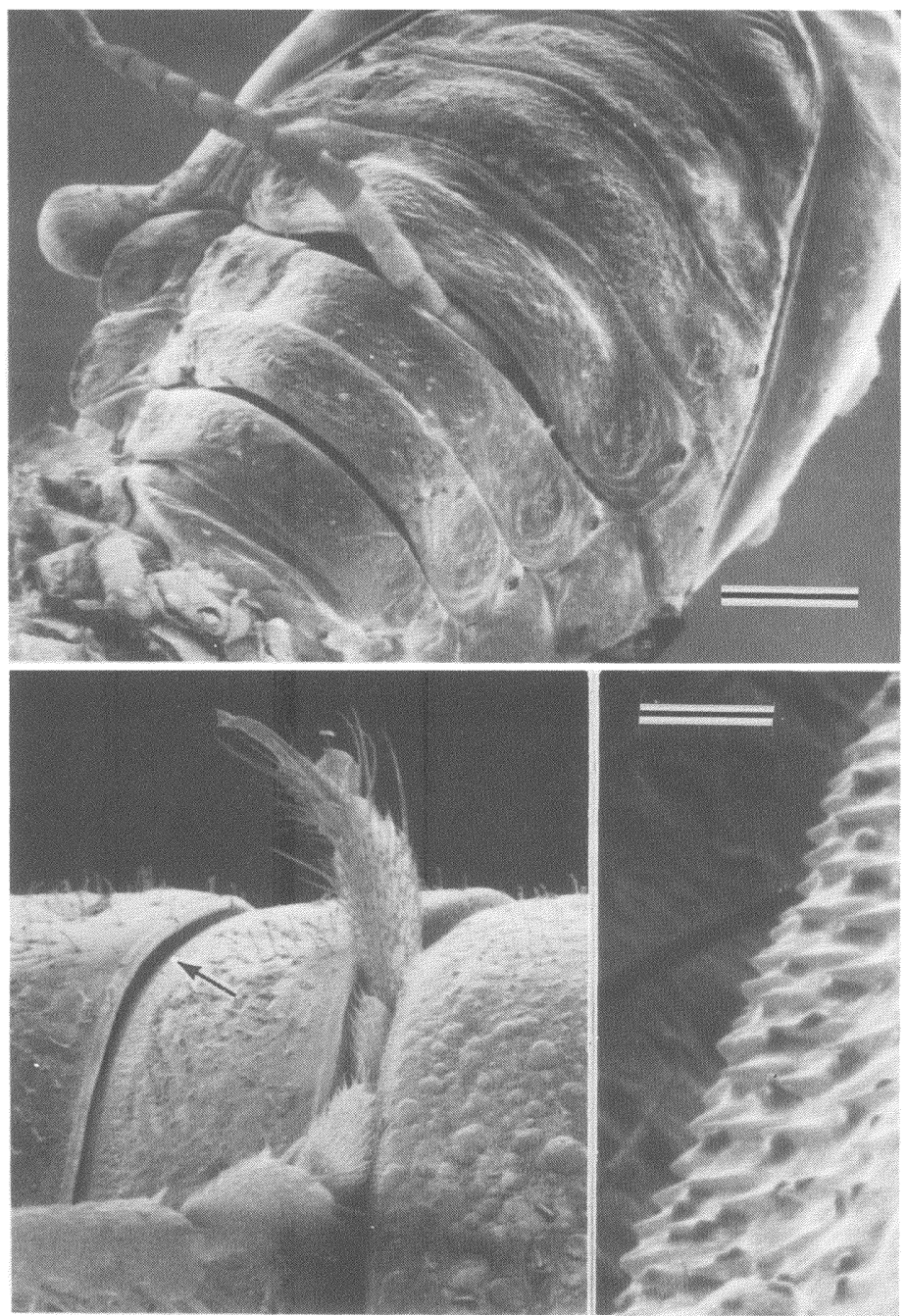

Figure 3. (Scanning electronmicrographs) (Top) Dorsal view of $C$. sanguinea pupa that has just been caused to flip in response to the antennal probings of a tethered ant. An antenna of the ant is seen caught in the squeeze of the anteriormost gin trap. (Bottom left) Comparable to preceding, showing a leg of an ant being pinched by a trap. (Bottom right) Detail of margin of anterior "jaw" of a gin trap (region denoted by arrow in picture on left), showing the typical serration. Reference bars: top $=0.5 \mathrm{~mm}$; bottom right $=10 \mu \mathrm{m}$. 
introduced into the chambers in groups of 12 to 15 . The pupae, presented one to a chamber, were still anchored to a piece of the twig on which they had pupated. To secure the twig in place, it was fastened with a strip of tape to a small glass platform (circular cover slip, $18 \mathrm{~mm}$ diameter), placed in the center of the chamber. The twig was oriented on the platform in such fashion as to insure dorsal-side-up positioning of the pupa. Tests were of $5 \mathrm{~min}$ duration, timed from the moment of introduction of the pupal preparation into the chamber. Five replicate tests were carried out, each with a different pupa and different set of ants. Events were verbally related into a tape recorder and subsequently transcribed.

The following data were noted for each test: (i) the incidence of encounters (the number of times that an ant came upon the pupa and proceeded to palpate it, walk over it, or attempt to bite it); (ii) the incidence of pupal response (the number of times that encounters resulted in the pupa reacting by flipping); and (iii) the flips per response (the number of consecutive flips executed by the pupa with each response).

The results are shown in Figure 4. Incidence of pupal response to ant encounters was high, ranging from $55 \%$ to $100 \%$. On average the pupae flipped more than once when they responded. Up to 7 flips per response were noted.

The ants were clearly deterred by the pupal response (Fig. 2, bottom). Most ants simply departed the moment flipping commenced, but a few were literally flung away by the flipping action. On two occasions it was noted that an ant was physically pinched by a gin trap during a flip; both instances involved pinchings of antennae. Additional such pinchings could have occurred, but could have gone unnoticed due to the quickness of the action. On five separate occasions ants were seen to bite or attempt to bite the pupa (in once case, involving an ant biting the head region of the pupa, a droplet of blood was drawn). None of the ants was observed to sting the pupae.

All five pupae eventually produced viable adults. One pupa emerged 12 hours after testing, indicating that even after virtual completion of adult development within the pupal shell, pupae are still able to defend themselves by flipping.

A few observations were also made at the Arizona site, with local $C$. sanguinea pupae and the ant Aphaenogaster albisetosa. 


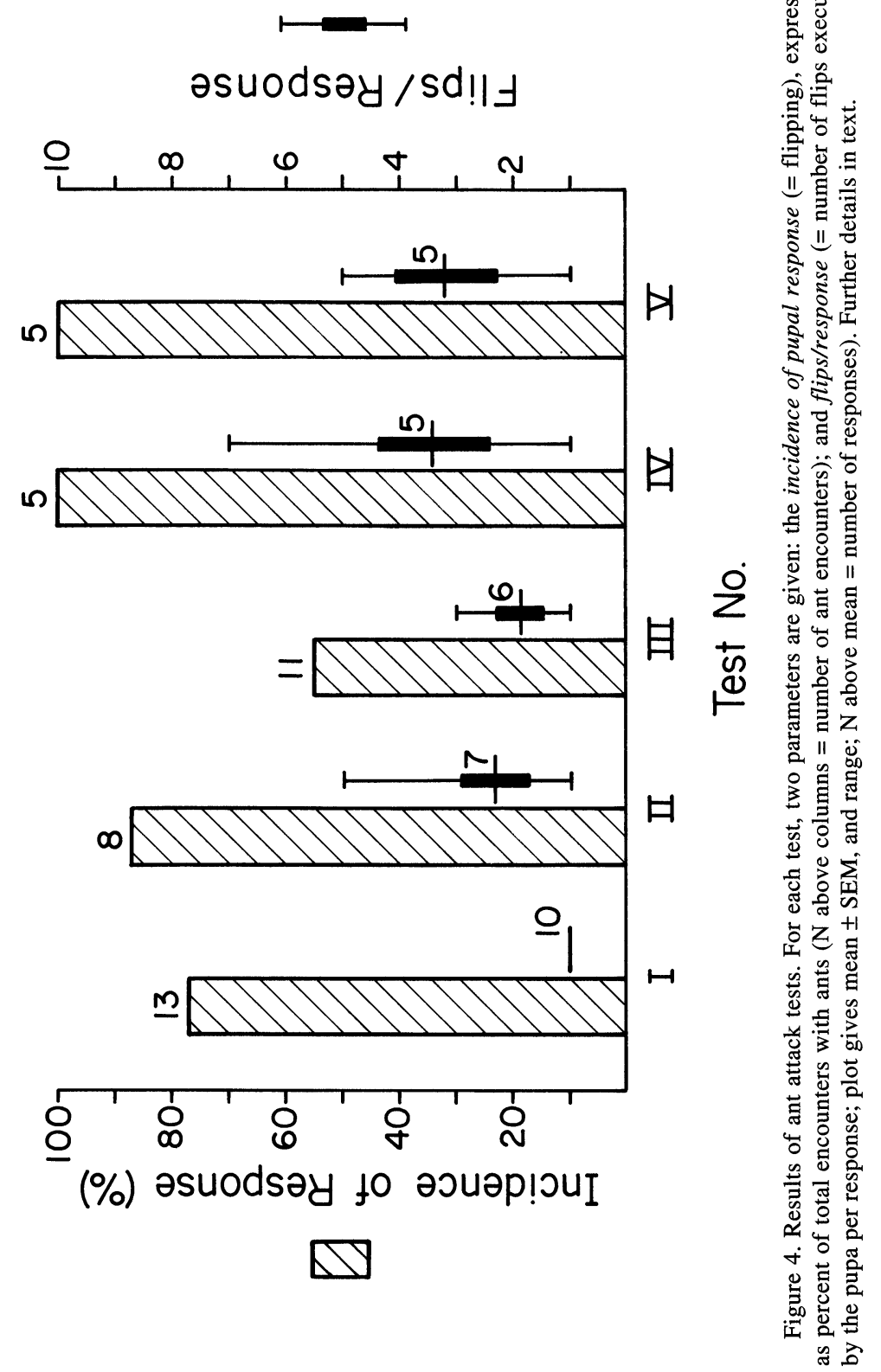


Pupae were presented to groups of the ant in plastic chambers as in the preceding test, with similar results. The ants caused the pupae to flip, and the flippings deterred the ants. On several occasions it appeared that ant appendages had been pinched by gin traps in the course of the flippings.

An additional observation confirmed that tactile stimulation by ants is an effective trigger of the flipping response. Individual ants of several unidentified species were tethered to the heads of insect pins (with a dab of wax placed on the alitrunk) and brought to touch the surface of pupae with their flailing legs and antennae. Contact usually induced one or more flippings. The touch of even a single antenna seemed at times sufficient to elicit a response. The most sensitive pupal region appeared to be the dorsal abdominal surface, where the gin traps are located.

A few pupae were immobilized by abrupt immersion in chilled liquid Freon 22 (technique in Eisner and Eisner, 1989), at the very moment that one of their gin traps had closed on an appendage of a tethered ant. Scanning electronmicroscopic examination of such pupae revealed the pinching action of the traps in graphic detail (Fig. 3).

\section{CONCLUSIONS}

The flipping behavior of $C$. sanguinea pupae is evidently defensive. Ants are deterred by the maneuver itself, as well as by its concomitant, the pinching action of the gin traps. Other insect predators (as well as parasitoids?) may be deterred as well, but ants are probably among the principal enemies of coccinellid pupae.

While, as noted by Hinton (1955), gin traps are widely distributed in Coccinellidae, they are not universally present in pupae of the family. Pupae of the Mexican bean beetle (Epilachna varivestis), for example, lack the traps, but they possess an alternative defense in the form of a covering of glandular hairs. The secretion associated with these hairs contains an interesting novel compound, currently under investigation (A. Attygalle, C. Blankespoor, J. Meinwald, T. Eisner, unpublished).

Gin traps have been the subject of little physiological work, except in Sphingidae, where much has been learned from studies of the neuronal control and development of control of the pupal 
gin trap reflex (see, for instance, Levine et al. 1986, Levine 1989, and Waldrop and Levine 1989). Coccinelid gin traps could doubtless also lend themselves to further study.

\section{ACKNOWLEDGEMENTS}

We thank the staff of the Archbold Biological Station for much help, and especially Mark Deyrup, who identified our Florida specimens of $C$. sanguinea, and provided some of the field-collected larvae. Our Arizona specimens were identified by Richard Hoebeke. Support by NIH grant AI-02908 and Hatch grant NYS191402 is gratefully acknowledged.

\section{Literature Cited}

EISNER, T. AND M. EISNER

1989. "Live" action scanning electron microscopy. Bull. Entomol. Soc. Amer. 35: 9-11.

GORDON, R. D.

1985. The Coccinellidae (Coleoptera) of America north of Mexico. J. New York Entomol. Soc. 93: 1-912.

HinTON, H. E.

1946. The "gin traps" of some beetle pupae; a protective device which appears to be unknown. Trans. Roy. Entomol. Assoc. London 97: 473-496.

1951. On a little-known protective device of some chrysomelid pupae (Coleoptera). Proc. Roy. Entomol. Soc. London (A) 26: 67-73.

1955. Protective devices of endopterygote pupae. Trans. Soc. British Entomol. 12: 49-92.

LEVINE, R. B.

1989. Expansion of the central arborization of persistent sensory neurons during insect metamorphism: the role of the steroid hormone 20hydroecdysone. J. Neurosc. 9: 1045-1054.

Levine, R. B., J. W. Truman, D. Linn, and C. M. Bate

1986. Endocrine regulation of the form and function of axonal arbors during insect Manduca sexta metamorphosis. J. Neurosc. 6: 293-299.

WALDROP, B. AND R. B. LEVINE

1989. Development of the gin trap reflex in Manduca sexta: a comparison of larval and pupal motor responses. J. Comp. Physiol. (A) 165: 743-754. 

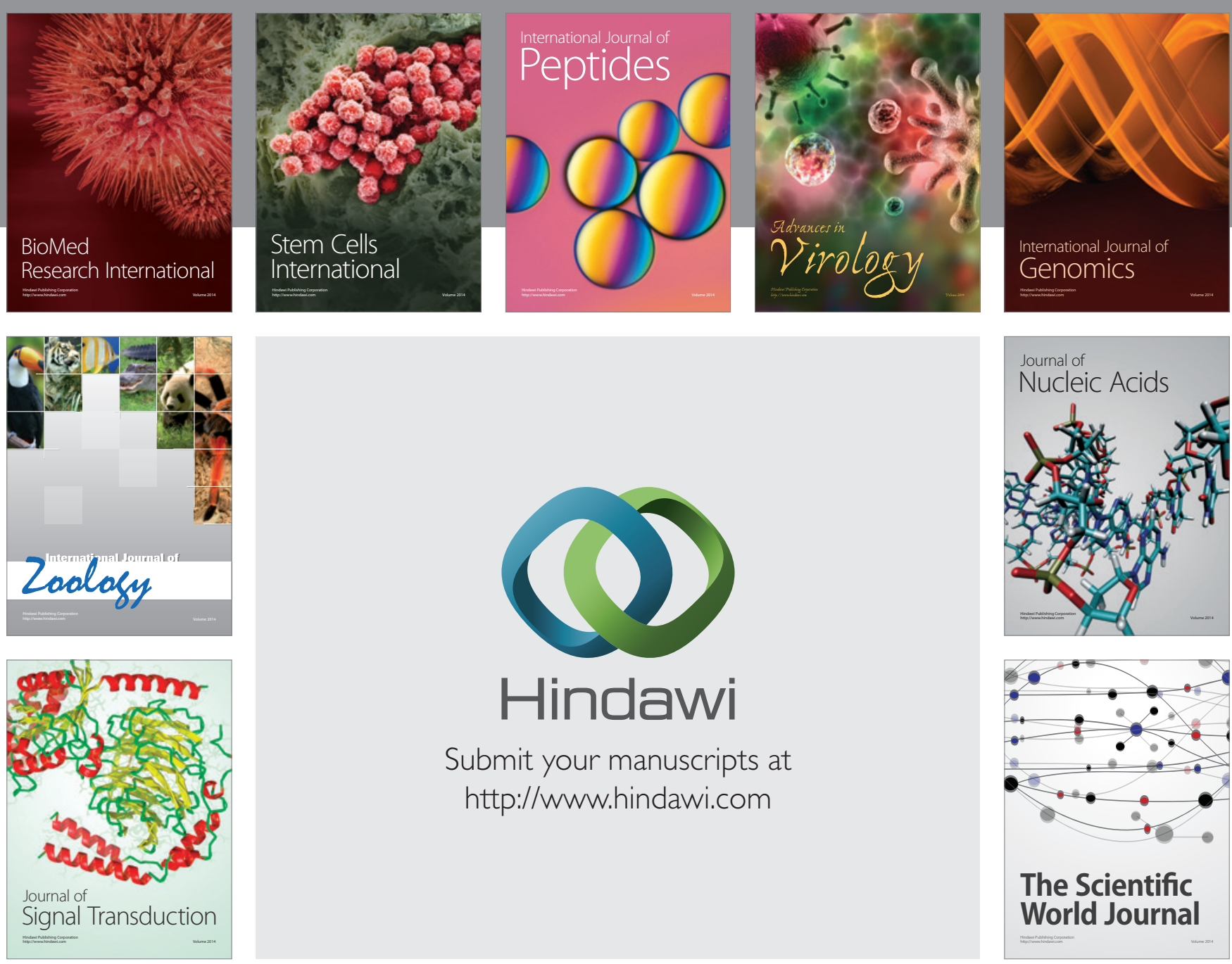

Submit your manuscripts at

http://www.hindawi.com
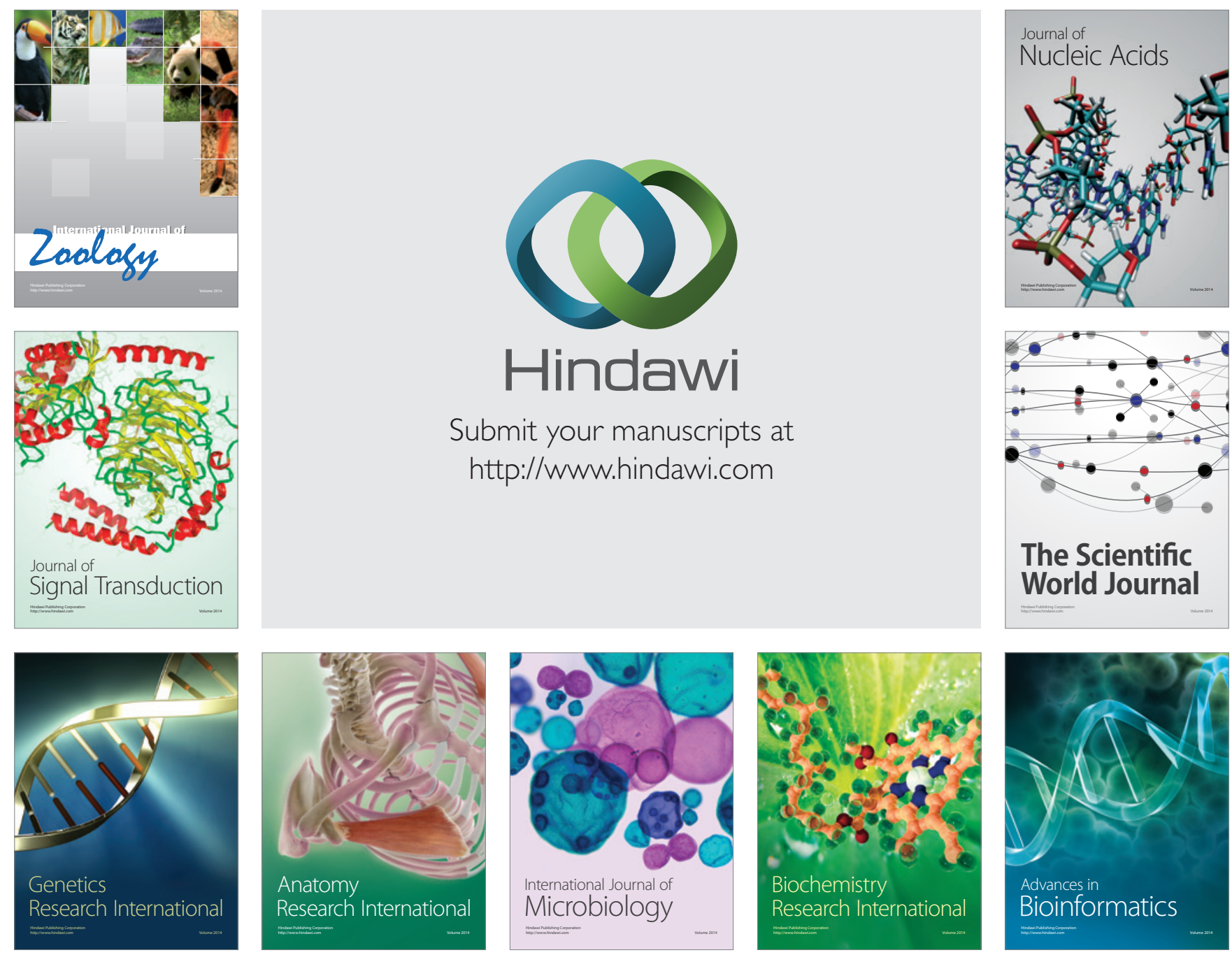

The Scientific World Journal
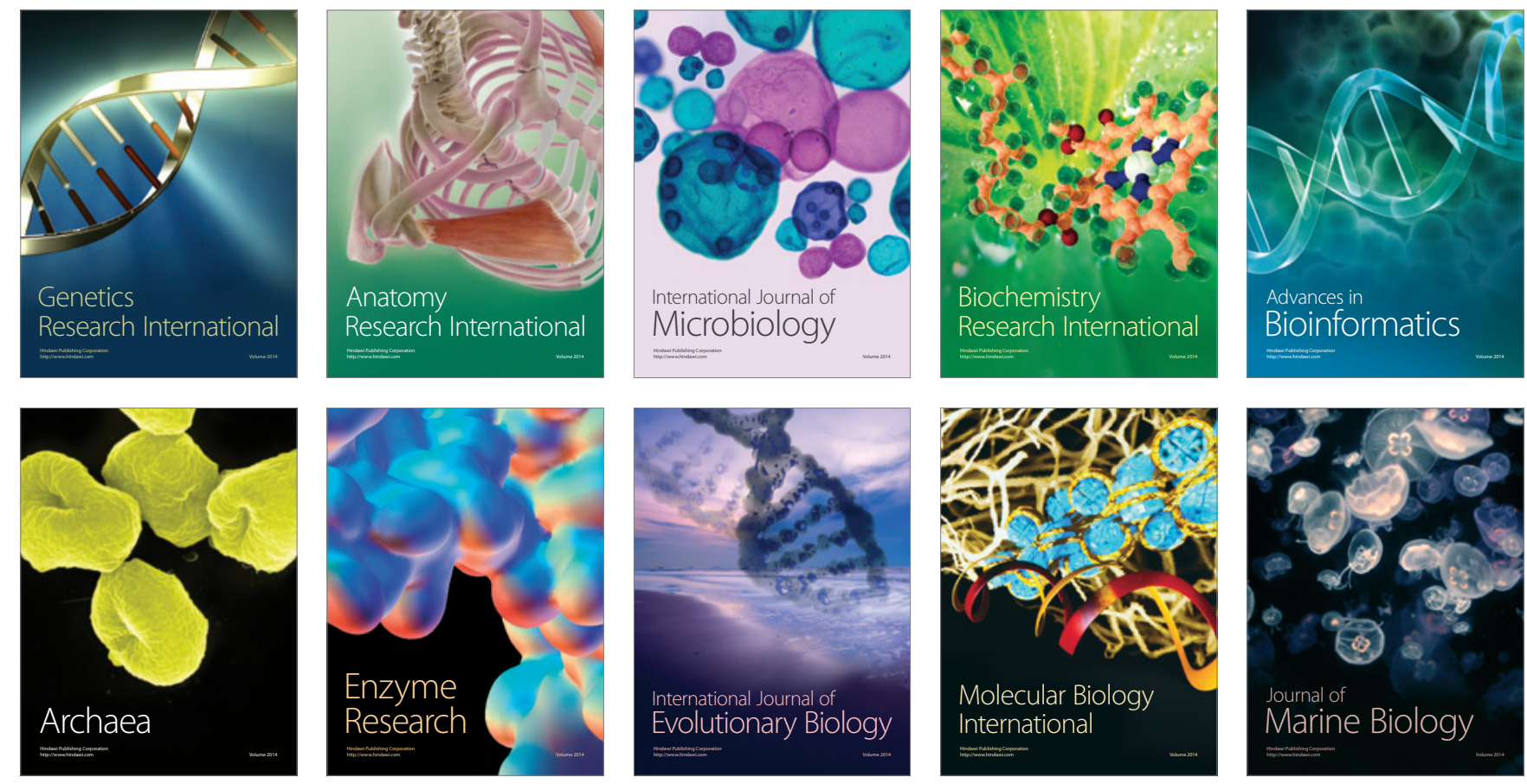